\title{
Pathologic evaluation of tumor-associated macrophage density and vessel inflammation in invasive breast carcinomas
}

\author{
YOSHIHIRO MORITA $^{1 *}$, ROY ZHANG ${ }^{2 *}$, MACALL LESLIE $^{1}$, SMITA ADHIKARI $^{3}$, NAFIS HASAN $^{4}$, \\ INNA CHERVONEVA ${ }^{5}$, HALLGEIR RUI ${ }^{6}$ and TAKEMI TANAKA ${ }^{1,2}$

\begin{abstract}
${ }^{1}$ Stephenson Cancer Center, ${ }^{2}$ Department of Pathology, School of Medicine, ${ }^{3}$ Department of Biostatistics and Epidemiology, College of Public Health, University of Oklahoma Health Sciences Center, Oklahoma City, OK 73104; Departments of ${ }^{4}$ Pharmaceutical Sciences and ${ }^{5}$ Pharmacology and Experimental Therapeutics, Thomas Jefferson University,
\end{abstract} \\ Philadelphia, PA 19107; ${ }^{6}$ Department of Pathology, Medical College of Wisconsin Cancer Center, Milwaukee, WI 53226, USA
}

Received March 9, 2017; Accepted May 16, 2017

\section{DOI: $10.3892 / \mathrm{ol} .2017 .6466$}

\begin{abstract}
Tumor-associated macrophages (TAMs) are major constituents of the tumor microenvironment in solid tumors and have been implicated as mediators of tumor progression, invasion and metastasis. Correspondingly, accumulation of TAMs is associated with unfavorable clinical outcomes in numerous types of solid tumors. E-selectin is a hallmark of inflammation and a key adhesion molecule that accommodates the initial contact of circulating immune cells with the inflamed vessel surface. Currently, the association between E-selectin and TAMs is not fully elucidated; therefore, the present study investigated the association between vessel inflammation, TAM infiltration, and clinical outcome in breast cancer. A total of 53 procedure-naïve invasive breast cancer cases were immunohistochemically analyzed for the presence of cluster of differentiation (CD) $68^{+}$TAMs, E-selectin ${ }^{+}$vessels and tumor inflammation. The association between CD68 and E-selectin expression, and tumor inflammation as well as overall survival was evaluated using Kaplan-Meier survival curves and multivariable Cox's proportional hazards regression analysis. The abundance of TAMs was identified to be positively associated with tumor inflammation, estrogen receptor and E-selectin expression levels. A greater prevalence of TAMs and tumor inflammation was significantly associated with shorter overall survival times. E-selectin expression levels were significantly higher in tumor vessels among elderly patients, but were not associated with overall survival. The abundance of TAMs
\end{abstract}

Correspondence to: Dr Takemi Tanaka, Stephenson Cancer Center, University of Oklahoma Health Sciences Center, Room 1415, 975 NE 10th, BRC-W, Oklahoma City, OK 73104, USA

E-mail: takemi-tanaka@ouhsc.edu

*Contributed equally

Key words: E-selectin, cluster of differentiation 68, tumorassociated macrophages, breast cancer, inflammation, overall survival, immnohistochemistry was associated with the presence of E-selectin-expressing inflamed tumor vessels and tumor inflammation, as well as overall survival in patients with invasive breast carcinoma.

\section{Introduction}

Inflammation is a hallmark of cancer, not only triggering tumor development, but also promoting tumor progression, therapy resistance and metastasis $(1,2)$. Breast cancer is a common type of malignancy, with $>1.67$ million new cases and 522,000 mortalities reported in 2012 worldwide (3). Approximately $30 \%$ of females with breast cancer experience recurrence within 5 years, with a $50 \%$ chance of developing distant metastases $(4,5)$. Cancer is aptly described as a wound that never heals since solid tumors are chronically inflamed and immune cells in concert with other stromal components influence cancer cell behavior. Immune infiltrates represent a significant component of the mass in solid tumors (6) and aid in regulating cancer cell growth, angiogenesis and invasion via the production of an array of cytokines, reactive oxygen species, and proteases (7-10). Tumor-associated macrophages (TAMs) are a prominent component, serving a central role in promoting tumor growth and metastasis (1). Accordingly, a greater abundance of TAMs has been associated with metastasis and poor prognosis in numerous types of solid tumors including breast $(11,12)$, lung $(13,14)$, prostate $(15)$, colorectal, and pancreatic cancer (16-19). TAMs are recognized as potent producers of growth factors (transforming growth factor- $\beta$, fibrobast growth factors and epidermal growth factor), pro-angiogenic factors [vascular endothelial growth factor, tumor necrosis factor- $\alpha$ (TNF- $\alpha$ ), interleukin (IL)-8, matrix metalloproteinase and platelet derived growth factor], proteases (cathepsin and serine proteases) and cytokines (IL-10), which profoundly affect epithelial cancer cell growth, angiogenesis, local invasion, extracellualr matrix degradation, epithelial-mesenchymal transition, metastasis, therapy response, and immunosuppression (20-22).

Macrophages originate from peripheral blood mononuclear cells derived from bone marrow and are recruited into the tumor via colony stimulating factor 1 and $\mathrm{C}-\mathrm{X}-\mathrm{C}$ motif chemokine ligand 12 , released from cancer cells or the tumor 
microenvironment (23). For successful tissue migration, circulating immune cells undergo a sequential multistep adhesion cascade initiated by adhesion to the vessel surface (24-28). Vascular expression of selectin family member proteins aids physical interaction with counter-receptor ligands expressed on immune cells, including sialyl Lewis ${ }^{\mathrm{x}}\left(\mathrm{sLe}^{\mathrm{x}}\right)$, sialyl Lewis $^{\mathrm{A}}\left(\mathrm{sLe}^{\mathrm{A}}\right)$, cluster of differentiation $(\mathrm{CD}) 44$, cutaneous lymphocyte-associated antigen and P-selectin glycoprotein ligand-1 (29-31). E-selectin (also known as CD62E, endothelial cell leukocyte adhesion-1 or Leukocyte-endothelial cell adhesion molecule 2) is exclusively expressed on the luminal surface of inflamed vessels and serves a role in the catch bond that switches from rolling adhesion to integrin-mediated firm adhesion (32). Thus, elevated vascular E-selectin expression levels have been reported in a range of solid tumors, including breast $(11,12)$, lung $(13,14)$ and pancreatic $(16,18)$ cancer. E-selectin expression often synchronizes with an abundance of $\mathrm{sLe}^{\mathrm{x}}$ - or $\mathrm{SLe}^{\mathrm{A}}$-positive immune infiltrates in the tumor $(33,34)$. The present study investigated the abundance of tumor vascular E-selectin and macrophage marker CD68 expression levels in order to understand the association between inflamed tumor vessels and TAM infiltration, as well as their role in breast cancer prognosis.

\section{Materials and methods}

Tumors. Surgical whole mounts from a total of 100 human breast carcinoma specimens from females diagnosed between January 1987 and December 1988 from the pathology archives at Thomas Jefferson University (Philadelphia, USA) were used in the present study. The average age of patients at the time of surgery was $61.8 \pm 16.4$ years. Cases with tissue containing ductal carcinoma in situ (DCIS) only, inflammatory breast cancer or other concurrent malignancies were excluded from the present study. Cases with no reactivity to vimentin staining were eliminated from the study. Only cases with fully annotated information regarding demographics, estrogen receptor (ER) expression, histology grade and overall survival (OS) were used in final analyses.

Immunohistochemistry. For quality control, cases were first immunohistochemically stained with anti-vimentin monoclonal antibody (cat. no. 550513; BD Biosciences, San Jose, CA, USA) at a 1:250 dilution overnight at $4^{\circ} \mathrm{C}$. Those without vimentin reactivity were removed from the study. Double immunohistochemistry was performed using formalin-fixed paraffin-embedded tumor sections ( $4 \mu \mathrm{m}$ thickness). Briefly, following deparaffinization and rehydration, antigen retrieval was performed using Envision Flex Target Retrieval Solution (pH 6.1; Dako; Santa Clara, CA, USA) in a pressure cooker for $20 \mathrm{~min}$ at $102^{\circ} \mathrm{C}$. Endogenous peroxidase and nonspecific epitopes were blocked with $0.3 \%$ hydrogen peroxide in absolute methanol for $30 \mathrm{~min}$ at room temperature and 5\% normal horse serum and $1 \%$ normal goat serum (Sigma-Aldrich; St. Louis, MO, USA) for $1 \mathrm{~h}$ at room temperature. Sections were incubated with mouse anti-E-selectin monoclonal antibody at 1:100 (cat. no. MO20039; Neuromics, Inc., Minneapolis, MN, USA) overnight at room temperature. Following washing with PBS and subsequent blocking with $5 \%$ normal horse serum and $1 \%$ normal goat serum for $5 \mathrm{~min}$ at room temperature, the slides were incubated with pre-dilute secondary horseradish peroxidase (HRP)-polymer conjugated anti-mouse IgG (cat. no. K4001; Dako) for $30 \mathrm{~min}$ at room temperature. HRP was detected using 3-3'-diaminobenzidine (DAB; Biocare Medical LLC, Paheco, CA, USA) substrate for $10 \mathrm{~min}$ at room temperature and enhanced using DAB Sparkle (Biocare Medical LLC) for $1 \mathrm{~min}$ at room temperature. Residual antibodies were eluted using Denaturing solution (Biocare Medical LLC) at a 1:3 dilution for $3 \mathrm{~min}$ at room temperature to ensure no cross reaction between the first and second staining. Slides were blocked with 5\% normal horse serum and $1 \%$ normal goat serum for $5 \mathrm{~min}$ at room temperature and then incubated with mouse anti-CD68 monoclonal antibody at 1:25 (cat. no. M0876; Dako) overnight at $4^{\circ} \mathrm{C}$. Following a brief wash with PBS, the slides were incubated with pre-dilute secondary alkaline phosphatase-polymer conjugated MACH2 anti-mouse IgG (cat. no. MALP521; Biocare Medical LLC) for $1 \mathrm{~h}$ at room temperature and then visualized using Fast-Red (Biocare Medical LLC) for $7 \mathrm{~min}$, followed by counterstain with Mayer Hematoxylin (Dako) for $4 \mathrm{~min}$ both at room temperature. The slides were air-dried and mounted. As a negative control, breast carcinoma tissues were immunostained with the secondary $\operatorname{IgG}$ only.

Pathologic evaluation. All immunohistochemically stained slides were evaluated by a board certified surgical pathologist (Department of Pathology, School of Medicine, University of Oklahoma Health Sciences Center, Oklahoma City, OK, USA) for breast pathology. The tumors were classified and graded according to the protocol from of the College of American Pathologists (Protocol for the Examination of Specimens from Patients with Invasive Carcinoma of the Breast according to InvasiveBreast 3.3.0.0.) (35). Tumor inflammation was defined as positive or negative, as characterized by the presence of lymphocyte clusters. Immunohistochemical reaction to E-selectin was graded using intensity as a score of $0,1+, 2+$ or $3+$ for no, weak, moderate or strong reaction in endothelial cells within the tumor, respectively. Immunohistochemical staining of CD68 was quantitatively categorized as a score of $0,1+, 2+$ or $3+$ for no $\mathrm{CD}^{+} 8^{+}$cells, $\leq 10 \mathrm{CD} 8^{+}$cells, $11-20 \mathrm{CD}^{+} 8^{+}$cells or $\geq 21 \mathrm{CD}^{+} 8^{+}$cells in the observing field at $\mathrm{x} 200$ magnification within the tumor, respectively. All images were viewed under a light microscope (DM2500; Leica, Buffalo Grove, IL, USA) and images were captured using digital cooling color camera (DFC450; Leica).

Statistical analysis. The Fisher's exact test was used to analyze the association between age and tumor pathological parameters using CD68 and E-selectin expression levels. Spearman's rho was used to determine the correlation between CD68 ${ }^{+} \mathrm{TAMs}$, and E-selectin expression level and tumor inflammation. The Kaplan-Meier method was used to estimate OS as a function of time, and differences were analyzed using the log-rank test. Cox proportional hazards regression analysis was used for multivariable analysis of prognostic factors in relation to OS. The statistical software SAS, version 9.4 (SAS Institute Inc., Cary, NC, USA) was used to perform statistical analyses. GraphPad Prism version 6 (Graphpad Software, Inc., La Jolla, CA, USA) was used to generate Kaplan-Meier curves. $\mathrm{P}<0.05$ was considered to indicate a statistically significant difference. 
Table I. Association between clinicopathologic parameters, and CD68 and E-selectin expression in procedure-naïve invasive breast carcinoma tissues.

\begin{tabular}{|c|c|c|c|c|c|c|c|}
\hline \multirow{2}{*}{$\begin{array}{l}\text { Clinicopathologic } \\
\text { parameters }\end{array}$} & \multirow{2}{*}{$\begin{array}{l}\text { Total no. } \\
\text { cases }\end{array}$} & \multicolumn{3}{|c|}{ CD68 expression } & \multicolumn{3}{|c|}{ E-selectin expression } \\
\hline & & Low & High & P-value & Low & High & P-value \\
\hline All cases & 53 & 34 & 19 & & 41 & 12 & \\
\hline Age & & & & 0.349 & & & $0.016^{\mathrm{a}}$ \\
\hline$\leq 60$ & 20 & 14 & 6 & & 19 & 1 & \\
\hline$>60$ & 33 & 20 & 13 & & 22 & 11 & \\
\hline Tumor inflammation & & & & $0.005^{\mathrm{a}}$ & & & 0.540 \\
\hline$(-)$ & 25 & 21 & 4 & & 19 & 6 & \\
\hline$(+)$ & 28 & 13 & 15 & & 22 & 6 & \\
\hline Nottingham histological grade & & & & 0.561 & & & 0.455 \\
\hline Grade I & 3 & 8 & 4 & & 3 & 0 & \\
\hline Grade II + III & 50 & 26 & 15 & & 38 & 12 & \\
\hline ER status & & & & $0.037^{\mathrm{a}}$ & & & 0.521 \\
\hline Negative & 11 & 4 & 7 & & 9 & 2 & \\
\hline Positive & 42 & 30 & 12 & & 32 & 10 & \\
\hline
\end{tabular}

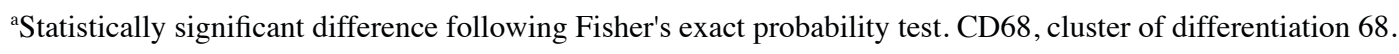

\section{Results}

Tumor characteristics. Following exclusions, a total of 53 invasive breast cancer cases that had been first-time diagnosed by surgical resection in 1986-1988 at Thomas Jefferson University were used in the present study. Tumor characteristics of these patients are presented in Table I. Cases were categorized as either high (score $3+$ ) or low (score $0-2+$ ) CD68 expression level according to the abundance of CD68 $8^{+}$TAMs in the tumor core and high (score $3+$ ), or low (score $0-2+$ ) expression level of E-selectin on vessels in the tumor area. CD68 ${ }^{+}$TAMs were significantly associated with tumor inflammation $(\mathrm{P}=0.005)$ and ER status $(\mathrm{P}=0.037)$. E-selectin expression level was associated with age $(\mathrm{P}=0.016)$ and was significantly higher among females over the age of 60 years (Table I).

Pattern of CD68 ${ }^{+}$TAM infiltration and E-selectin ${ }^{+}$vessel inflammation in breast tumors. Representative images of high and low expression levels of CD68+ TAMs, and E-selectin ${ }^{+}$inflamed vessels are presented in Fig. 1. Various expression levels of CD68 ${ }^{+}$TAMs were consistently present in the tumor stroma and core of all 53 cases (Fig. 1A-C). Considerable, multilayered $\mathrm{CD} 68^{+} \mathrm{TAM}$ deposition in the necrotic area of the tumors was observed. CD68 ${ }^{+}$ TAMs were also abundant in the mammary fat adjacent to the tumor, as well as around the luminal surface of vessels (Fig. 1C). E-selectin was predominantly expressed on vessels within the tumor stroma (Fig. 1D and E). No positive signal for E-selectin was detected in other tumor components, including cancer cells, fibroblasts, immune infiltrates or the apical side of the vessels. The size of E-selectin-expressing vessels varied from small capillaries to large vessels in the stroma and fat adjacent to the invasive front of tumors. Vessel structure was well retained within the stroma but often compressed, crushed or even absent in the tumor core. Overall, $88.7 \%$ of the breast carcinoma cases exhibited E-selectin expression on their tumor vessels. Consistent with inflammation of the adipose tissue adjacent to the tumor, E-selectin expression level was also high in vessels of the neighboring peripheral adipose tissue. Of note, vascular E-selectin expression level was present in the stroma surrounding the mammary duct in invasive carcinomas that retained a ductal structure (Fig. 1F). A similar pattern of E-selectin expressing vessels in the stroma around the mammary duct in DCIS only cases was also revealed (data not shown), suggesting the presence of peritumoral inflammation at the pre-invasive stage.

Association between vessel inflammation and TAM infiltration. Double immunohistochemistry for CD68 (pink) and E-selectin (brown) was performed to evaluate their association. $\mathrm{CD}^{6} 8^{+}$TAMs were abundant in close proximity to E-selectin-expressing vessels in the tumor stroma and peripheral tissue adjacent to the tumor (Fig. 2A and B). CD68 ${ }^{+}$TAMs were sparsely present in carcinoma cell rich areas; however, E-selectin expression was limited to the surrounding inflamed area and absent or weakly present in the tumor core (Fig. 2B). CD68 ${ }^{+}$TAMs were also highly abundant in necrotic areas, but E-selectin was absent within and adjacent to the necrotic core (Fig. 2C). TAMs and E-selectin were present at the location where the ductal structure was retained (Fig. 2D). Association between the abundance of $\mathrm{CD}^{2} 8^{+}$TAMs and E-selectin ${ }^{+}$ vessels was evaluated using a 4-level scoring scale $(0,1+, 2+$, $3+)$ for the expression level of each marker. High abundance of CD68 ${ }^{+}$TAMs and E-selectin ${ }^{+}$vessels $(3+/ 3+)$ was demonstrated in $7.5 \%$ of the overall analyzed samples. CD68 ${ }^{+}$TAMs and E-selectin expression levels were positively correlated ( $r=0.30, \mathrm{P}=0.030$; Table II). Additionally, CD68 ${ }^{+}$TAMs were 
A

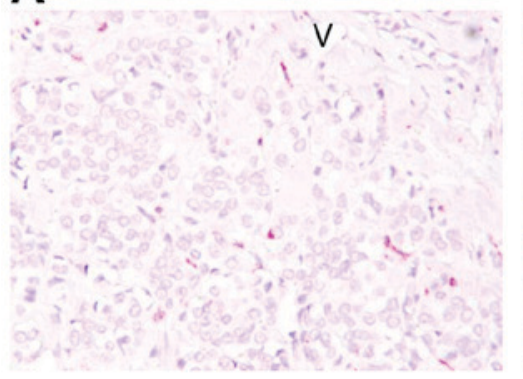

D

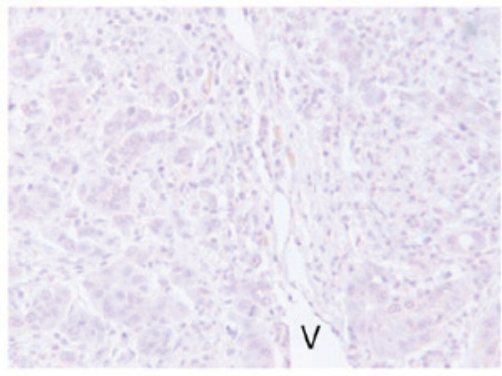

B

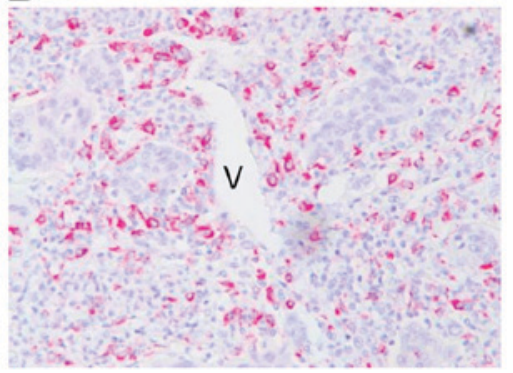

E

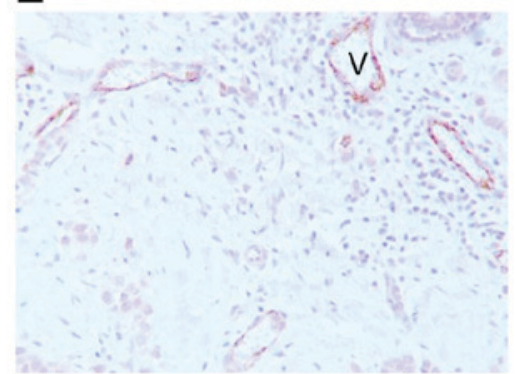

C

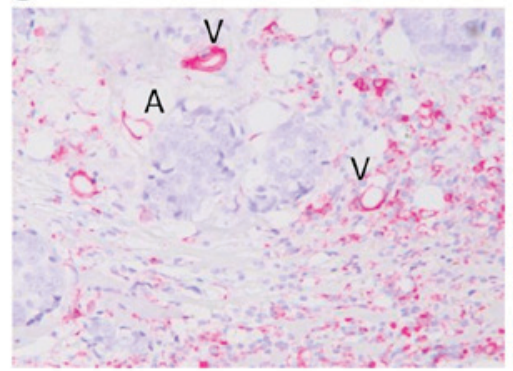

$\mathbf{F}$

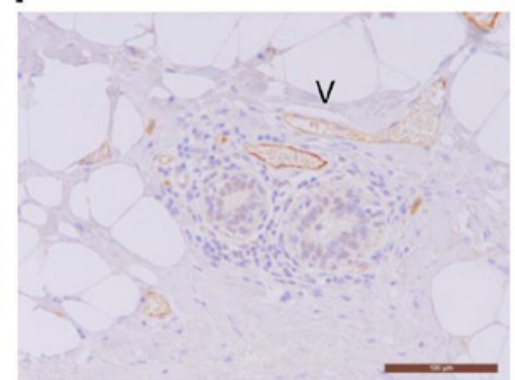

Figure 1. TAM and E-selectin expression levels in breast tumor tissues. (A-C) Single immunohistochemical staining of CD68 ${ }^{+}$TAMs for analysis of the distribution at various areas of the invasive breast carcinoma tissues (red). (D-F) Differential E-selectin expression in vessel surface in breast carcinomas (brown). The images are representative at a final magnification of x200. Scale bar indicates $100 \mu \mathrm{m}$. V, vessels; A, adipocytes; CD68, cluster of differentiation 68 .

A

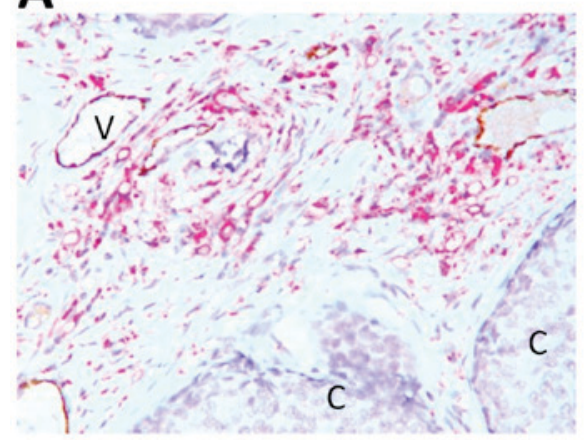

C

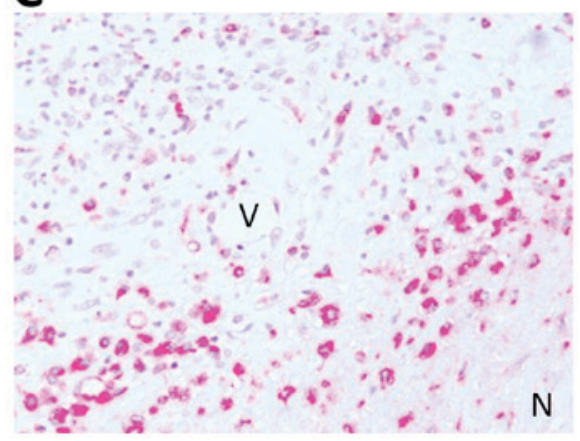

B

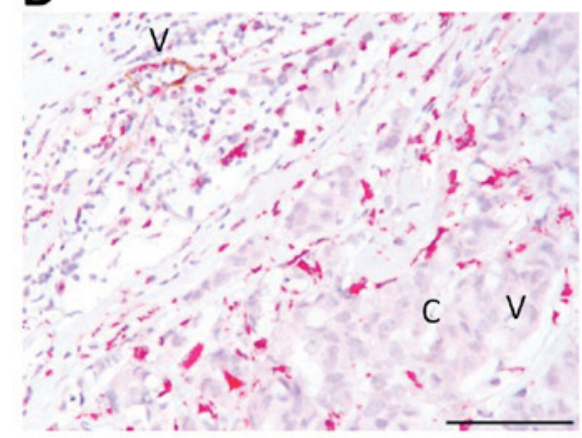

D

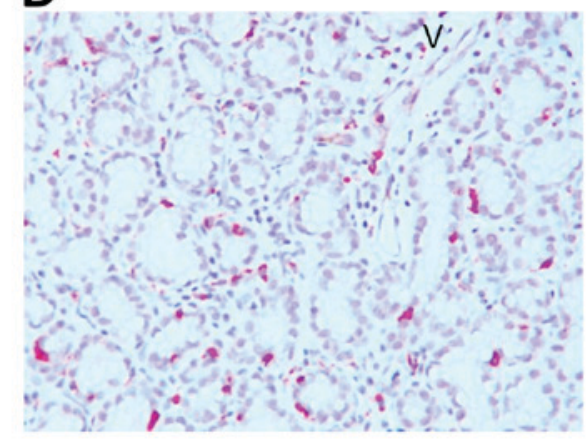

Figure 2. Double immunohistochemistry of TAM and E-selectin. (A and B) Spatial association of CD68 ${ }^{+}$TAM and E-selectin in the tumor stroma of invasive breast carcinoma tissues. (C) Absence of E-selectin expressing vessels in necrotic area. (D) Presence of CD68 ${ }^{+}$TAM and E-selectin in stroma of non-carcinoma area of invasive carcinoma tissue. Brown indicates E-selectin and red indicates TAM. The images are representative at a final magnification of x200. Scale bar indicates $100 \mu \mathrm{m}$. V, vessels; C, cancer cells; N, necrotic area; CD68, cluster of differentiation 68.

significantly correlated with tumor inflammation $(\mathrm{r}=0.54$, $\mathrm{P}=0.001$; Table II).

Abundance of markers and clinical outcome. OS was determined and graphically presented using the Kaplan-Meier method, and a Cox proportional hazards regression model was used for multivariable analysis of the association between clinicopathological parameters and marker expression level with OS. Tumor inflammation was significantly associated with OS among patients with breast cancer [hazard ratio 
Table II. Association between CD68 ${ }^{+}$TAMs, and E-selectin expressing vessels and tumor inflammation in procedure-naïve invasive breast carcinoma tissues.

\begin{tabular}{|c|c|c|c|c|c|c|}
\hline \multirow[b]{2}{*}{ CD68 } & \multicolumn{4}{|c|}{ E-selectin } & \multicolumn{2}{|c|}{ Inflammation } \\
\hline & 0 & $1+$ & $2+$ & $3+$ & - & + \\
\hline 0 & 0 & 0 & 0 & 0 & 0 & 0 \\
\hline $1+$ & 3 & 5 & 4 & 2 & 13 & 1 \\
\hline $2+$ & 1 & 6 & 10 & 3 & 8 & 12 \\
\hline \multirow[t]{2}{*}{$3+$} & 2 & 2 & 8 & 7 & 4 & 15 \\
\hline & & \multicolumn{3}{|c|}{$\begin{array}{c}{ }^{*} \mathrm{P}=0.030 \\
\mathrm{r}=0.302\end{array}$} & \multicolumn{2}{|c|}{$\begin{array}{c}{ }^{*} \mathrm{P}<0.001 \\
\mathrm{r}=0.541\end{array}$} \\
\hline
\end{tabular}

E-selectin: 0, no immunohistochemical reaction; $1+$, weakly; $2+$, moderately; $3+$, strong reactions in endothelial cells. CD68: 0, no CD68 ${ }^{+}$ cells; $1+, \leq 10 \mathrm{CD}^{+} 8^{+}$cells; $2+, 11-20 \mathrm{CD}^{2} 8^{+}$cells; $3+\geq 21 \mathrm{CD}^{+} 8^{+}$cells CD68, cluster of differentiation 68; TAMs, tumor-associated macrophages.

Table III. Multivariable Cox proportional hazard regression analysis of overall survival.

\begin{tabular}{|c|c|c|c|}
\hline Variables & P-value & $\begin{array}{c}\text { Hazard } \\
\text { ratio }\end{array}$ & $95 \% \mathrm{CI}$ \\
\hline $\begin{array}{l}\text { Tumor inflammation } \\
\text { (ref. positive) }\end{array}$ & 0.326 & 1.48 & $0.68-3.26$ \\
\hline ER status (ref. negative) & 0.341 & 1.50 & $0.65-3.42$ \\
\hline E-selectin expression (ref. high) & 0.112 & 0.46 & $0.18-1.20$ \\
\hline CD68 expression (ref. high) & $0.045^{\mathrm{a}}$ & 2.34 & $1.02-5.36$ \\
\hline
\end{tabular}

astatistically significant. CI, confidence interval; ER, estrogen receptor; CD68, cluster of differentiation.

(HR), 2.00; confidence interval (CI) 95\%, 1.03-4.06; P=0.044; Fig. 3A]. However, inflammation in the tumor periphery lacked association with OS (HR, 1.20; CI 95\%, 0.560-2.61; P=0.629; data not shown). Compared with tissue samples with lower expression levels of CD68 ${ }^{+}$TAMs, higher expression levels of CD68 ${ }^{+}$TAMs in the tumor core were significantly associated with shorter OS at the 10-year follow-up (HR, 2.23; CI 95\%, 1.12-5.54; $\mathrm{P}=0.017$; Fig. 3B). Conversely, CD68 ${ }^{+}$TAMs in the tumor periphery were not significantly associated with OS (HR, 1.39; CI 95\%, 0.59-3.50; $\mathrm{P}=0.420$; data not shown). Although the abundance of E-selectin ${ }^{+}$vessels and $\mathrm{CD} 68^{+}$TAMs were positively correlated, E-selectin expression level alone did not impact OS at the tumor (HR, 0.71; CI 95\%, 0.32-1.57; $\mathrm{P}=0.395$; Fig. 3C) or periphery. Kaplan-Meier analysis demonstrated that OS was unaffected by age for CD68, E-selectin or tumor inflammation statuses (data not shown). Finally, multivariable analysis of procedure-naïve breast tumor tissues revealed that the presence of abundant $\mathrm{CD} 68^{+} \mathrm{TAMs}$ was an independent predictor of OS (HR, 2.37; 95\% CI, 1.02-5.36; $\mathrm{P}=0.045)$ following adjustment for ER status, tumor inflammation and E-selectin expression level (Table III).

\section{Discussion}

Tissue infiltration by circulating leukocytes occurs in response to tissue damage and injury. In the context of solid tumors, cell death arises from intrinsic and extrinsic inducers, initiating an inflammatory cascade in an attempt to scavenge debris, and repair damaged tissue. Intrinsic cell death is hypoxia-derived necrosis or DNA-damage-associated apoptosis, whereas extrinsic cell death is associated with external stimuli,including chemotherapy, biopsy, surgery or radiation therapy. The standard of care for breast cancer has altered significantly over the past 3 decades (35). Diagnostic needle biopsy became popular in the 1990s (36) and neoadjuvant chemotherapy for relatively large, locally advanced tumors emerged in the 2000s (37). Both procedures provoke inflammation accompanied by cell death in the tumor and neighboring peripheral tissue. Thus, it is likely that recent surgically resected tumors contain inflammation induced by extrinsic stress along with naturally occurring intrinsic cell death. Although external stress naïve tumors can be analyzed using biopsy samples, such samples contain only small and limited amounts of tissue, making the capture of the overall tumor environment difficult. Analysis of naïve tumors collected by excisional biopsy essentially eliminates locally advanced tumors since this method is typically only used in early stage small-sized tumors. Thus, in order to understand the association of vessel inflammation and TAM infiltration in intrinsic tumor inflammation, the present study specifically targeted surgically resected, procedure-naïve breast tumor tissue samples collected between 1986 and 1988, when needle biopsy was not yet broadly adopted as the standard of care.

The involvement of E-selectin in cancer has long been recognized, as evidenced by histopathological studies; however, its clinical implications have been controversial $(11,12,38)$. The results of the present study revealed that $88.7 \%$ of procedure-naïve breast tumors expressed E-selectin in the vessels within the tumor. Previously, the prevalence of E-selectin-positive vessels has been reported as $55.7 \%$ $(\mathrm{n}=113)(11)$ and $77.6 \%(\mathrm{n}=22)(12)$ in frozen breast tumor tissue sections. A previous study by Charpin et al (11) demonstrated a positive association between E-selectin expression level, and vascular cell adhesion molecule-1, very late antigen-2 and CD44 expression levels, and a negative association with E-cadherin expression level. However, the latter was postiviely associated with ER-negative breast cancer, which may be due to the release of higher expression levels of IL- 1 and TNF- $\alpha$ from ER-negative compared with ER-positive breast cancer cells. The present study and the study by Charpin et al (11) did not determine an association between E-selectin expression and ER status, but both studies identified an association between E-selectin, and $\mathrm{CD} 68^{+} \mathrm{TAMs}$ or $\mathrm{CD} 44^{+}$immune infiltrates, a common marker for immune cells.

TAMs are classified as either pro-inflammatory M1 or pro-tumorigenic M2 macrophages (36), although it is yet to be determined which of these is more clinically important for prognosis $(37,39)$. Unlike T-lymphocytes, whose phenotypes are classified by differentiation, the TAM phenotype is plastic and determined by its surrounding microenvironment (40). For example, the M1 phenotype can switch to M2 in response to $\mathrm{T}$ helper 2-released cytokines, including IL-13 and IL-4 (41). Accordingly, the overall composition and 

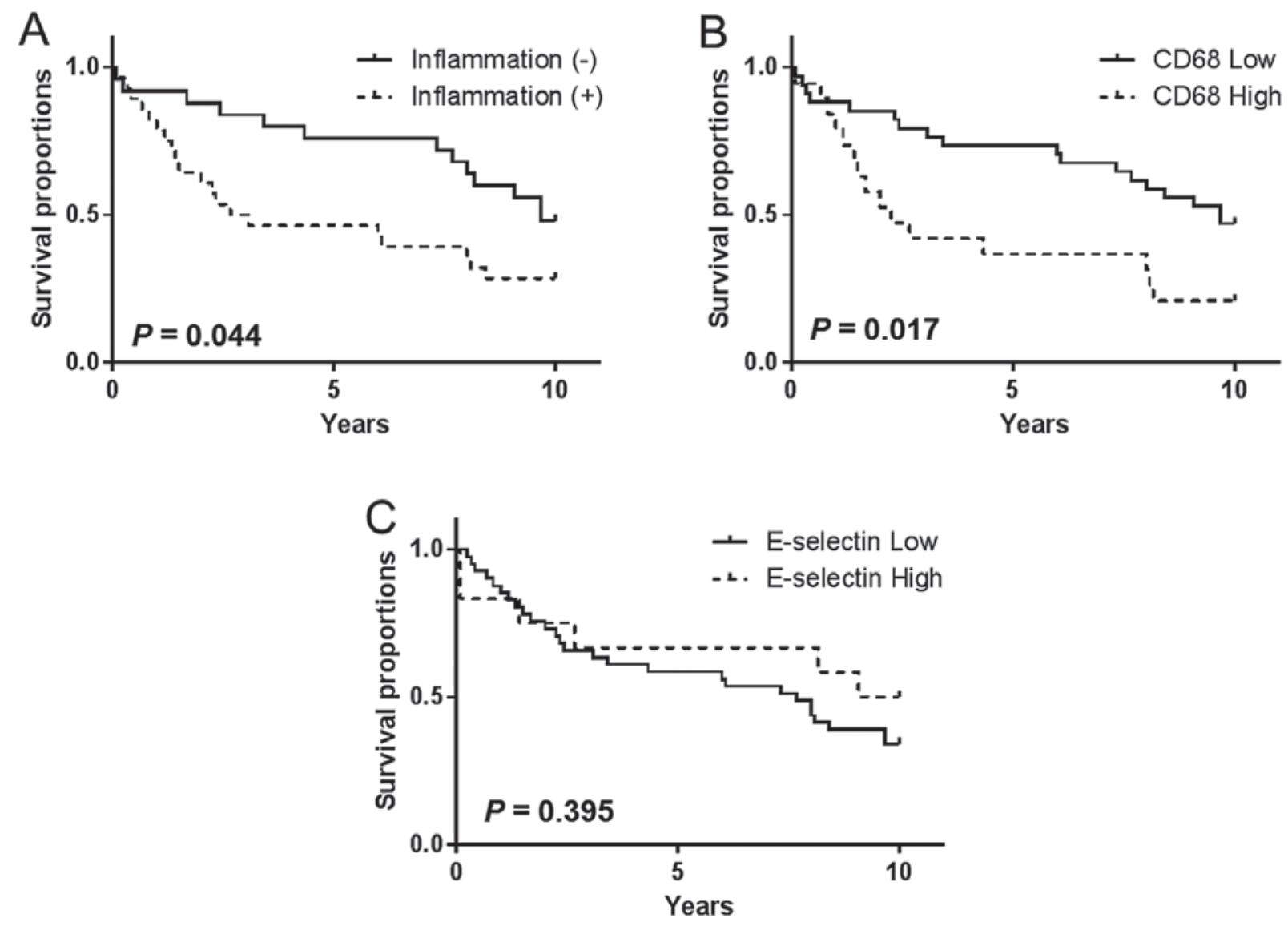

Figure 3. Overall survival by prevalence of (A) tumor inflammation, (B) TAM and (C) E-selectin. Kaplan-Meier survival curves according to tumor inflammation, CD68 ${ }^{+}$TAMs and E-selectin ${ }^{+}$vessels in 53 invasive patients with breast cancer. TAM, tumor-associated macrophage; CD68, cluster of differentiation 68 .

balance of immune subsets determines the pro-tumorigenic potential and fate of the tumor. TAMs were present in all procedure-naïve invasive breast carcinoma samples in the present study and their spatial distribution pattern, as well as abundance, differed among cases. TAMs were a predominant component near the necrotic core, in adipose tissue adjacent to the tumor and in the tumor stroma. Further investigation of TAM accumulation and phenotypic distribution at different locations may improve the understanding of their clinical implications.

E-selectin turnover is short, and it is shed into the circulation as a circulating form of E-selectin, soluble (s)E-selectin (42). sE-selectin has been used as a surrogate marker for vessel inflammation since sE-selectin expression levels appear to be associated with the vascular E-selectin present on the surface of the endothelial cells (43-48). For example, the sE-selectin expression level was significantly higher among patients with metastatic breast cancer compared with that of healthy counterparts $(33.5$ vs. $21.8 \mathrm{ng} / \mathrm{ml}$; $\mathrm{P}<0.01)$, as well as in patients with liver metastasis compared with those without $(55.3$ vs. $26.0 \mathrm{ng} / \mathrm{ml} ; \mathrm{P}<0.0001)$. Thus, increased expression levels of sE-selectin were associated with reduced overall survival in breast cancer (49). Similarly, pre-surgical sE-selectin expression levels were higher in patients with colorectal cancer (43 ng/ml) compared with patients with benign diseases (43 ng vs. $31 \mathrm{ng} / \mathrm{ml}$ ) and were positively associated with carcinoembryonic antigen tumor marker and poorer prognosis (both $\mathrm{P}<0.001)(50)$. However, a study of microarray data from 1,809 breast cancer patients with no previous treatment history revealed that E-selectin expression level was associated with longer survival times (HR, 0.67; CI $95 \%, 0.54-0.83 ; \mathrm{P}=0.001$ ) (51). In the present study, E-selectin expression level in breast tumor tissue samples was more abundant in females $>60$ years compared with those $\leq 60$. Elevated E-selection expression level among elderly females may be attributed to age-associated inflammation due to comorbidities, since sE-selectin expression levels are reported to be high in chronic inflammatory conditions, including arthritis (52,53), diabetes (52), atherosclerosis (54) and alcoholism (55). However, E-selectin expression level in the tumor was not associated with OS following age adjustment in the present study (data not shown). The survival implications of E-selectin expression may require integration of area-specific expression (tumor or necrosis vs. stroma), type of survival (overall vs. disease specific) and comorbidity status. In conclusion, tumor inflammation and E-selectin expression levels were identified to be positively correlated with TAMs, and the abundance of TAMs present in the tumor was an independent prognostic factor in invasive breast tumors.

\section{Acknowledgements}

The present study was supported by the National Institutes of Health (grant no. 1R01CA160271-01A1). The authors would like to thank Lynsie Morris for the technical assistance provided. 


\section{References}

1. Pollard JW: Tumour-educated macrophages promote tumour progression and metastasis. Nat Rev Cancer 4: 71-78, 2004.

2. Ruffell B and Coussens LM: Macrophages and therapeutic resistance in cancer. Cancer Cell 27: 462-472, 2015.

3. Ferlay J, Soerjomataram I, Ervik M, Dikshit R, Eser S, Mathers C, Rebelo M, Parkin DM, Forman D and Bray F: Cancer incidence and mortality worldwide: sources, methods and major patterns in GLOBOCAN 2012. Int Agency Res Cancer, 2014.

4. Newman EA and Newman LA: Lymphatic mapping techniques and sentinel lymph node biopsy in breast cancer. Surg Clin North Am 87: 353-364, viii, 2007

5. Redig AJ and McAllister SS: Breast cancer as a systemic disease: A view of metastasis. J Intern Med 274: 113-126, 2013.

6. Hanahan D and Weinberg RA: The hallmarks of cancer. Cell 100: $57-70,2000$.

7. Coussens LM and Werb Z: Inflammation and cancer. Nature 420 : $860-867,2002$.

8. Mantovani A, Allavena P, Sica A and Balkwill F: Cancer-related inflammation. Nature 454: 436-444, 2008.

9. Mueller MM and Fusenig NE: Friends or foes-bipolar effects of the tumour stroma in cancer. Nat Rev Cancer 4: 839-849, 2004.

10. Rakoff-Nahoum S: Why cancer and inflammation? Yale J Biol Med 79: 123-130, 2006

11. Charpin C, Bergeret D, Garcia S, Andrac L, Martini F, Horschowski N, Choux R and Lavaut MN: ELAM selectin expression in breast carcinomas detected by automated and quantitative immunohistochemical assays. Int $\mathrm{J}$ Oncol 12: 1041-1048, 1998.

12. Nguyen M, Corless CL, Kräling BM, Tran C, Atha T, Bischoff $\mathbf{J}$ and Barsky SH: Vascular expression of E-selectin is increased in estrogen-receptor-negative breast cancer: A role for tumor-cell-secreted interleukin-1 alpha. Am J Pathol 150: 1307-1314, 1997

13. Müller AM, Weichert A and Müller KM: E-cadherin, E-selectin and vascular cell adhesion molecule: Immunohistochemical markers for differentiation between mesothelioma and metastatic pulmonary adenocarcinoma? Virchows Arch 441: 41-46, 2002.

14. Staal-van den Brekel AJ, Thunnissen FB, Buurman WA and Wouters EF: Expression of E-selectin,intercellular adhesion molecule (ICAM)-1 and vascular cell adhesion molecule (VCAM)-1 in non-small-cell lung carcinoma. Virchows Arch 428: 21-27, 1996.

15. Bhaskar V, Law DA, Ibsen E, Breinberg D, Cass KM, DuBridge RB, Evangelista F, Henshall SM, Hevezi P, Miller JC, et al: E-selectin up-regulation allows for targeted drug delivery in prostate cancer. Cancer Res 63: 6387-6394, 2003.

16. Eichbaum MH, de Rossi TM, Kaul S and Bastert G: Serum levels of soluble E-selectin are associated with the clinical course of metastatic disease in patients with liver metastases from breast cancer. Oncol Res 14: 603-610, 2004.

17. Leek RD, Landers RJ, Harris AL and Lewis CE: Necrosis correlates with high vascular density and focal macrophage infiltration in invasive carcinoma of the breast. Br J Cancer 79: 991-995, 1999

18. Tozeren A, Kleinman HK, Grant DS, Morales D, Mercurio AM and Byers SW: E-selectin-mediated dynamic interactions of breast- and colon-cancer cells with endothelial-cell monolayers. Int J Cancer 60: 426-431, 1995

19. Tsutsui S, Yasuda K, Suzuki K, Tahara K, Higashi H and Era S: Macrophage infiltration and its prognostic implications in breast cancer: The relationship with VEGF expression and microvessel density. Oncol Rep 14: 425-431, 2005.

20. Leek RD and Harris AL: Tumor-associated macrophages in breast cancer. J Mammary Gland Biol Neoplasia 7: 177-189,2002.

21. Leek RD, Talks KL, Pezzella F, Turley H, Campo L, Brown NS, Bicknell R, Taylor M, Gatter KC and Harris AL: Relation of hypoxia-inducible factor-2 alpha (HIF-2 alpha) expression in tumor-infiltrative macrophages to tumor angiogenesis and the oxidative thymidine phosphorylase pathway in human breast cancer. Cancer Res 62: 1326-1329, 2002.

22. Lewis CE and Pollard JW: Distinct role of macrophages in different tumor microenvironments. Cancer Res 66: 605-612, 2006

23. Joyce JA and Pollard JW: Microenvironmental regulation of metastasis. Nat Rev Cancer 9: 239-252, 2009.

24. Berg EL, Robinson MK, Mansson O, Butcher EC and Magnani JL: A carbohydrate domain common to both sialyl Le(a) and sialyl $\mathrm{Le}(\mathrm{X})$ is recognized by the endothelial cell leukocyte adhesion molecule ELAM-1. J Biol Chem 266: 14869-14872, 1991.
25. Ley K, Laudanna C, Cybulsky MI and Nourshargh S: Getting to the site of inflammation: The leukocyte adhesion cascade updated. Nat Rev Immunol 7: 678-689, 2007.

26. Luster AD, Alon R and von Andrian UH: Immune cell migration in inflammation: Present and future therapeutic targets. Nat Immunol 6: 1182-1190, 2005.

27. Welply JK, Keene JL, Schmuke JJ and Howard SC: Selectins as potential targets of therapeutic intervention in inflammatory diseases. Biochim Biophys Acta 1197: 215-226, 1994.

28. Zetter BR: Adhesion molecules in tumor metastasis. Semin Cancer Biol 4: 219-229, 1993

29. Phillips ML, Nudelman E, Gaeta FC, Perez M, Singhal AK, Hakomori S and Paulson JC: ELAM-1 mediates cell adhesion by recognition of a carbohydrate ligand, sialyl-Lex. Science 250 : 1130-1132, 1990

30. Picker LJ, Kishimoto TK, Smith CW, Warnock RA and Butcher EC: ELAM-1 is an adhesion molecule for skin-homing T cells. Nature 349: 796-799, 1991

31. Shimizu Y, Shaw S, Graber N, Gopal TV, Horgan KJ, Van Seventer GA and Newman W: Activation-independent binding of human memory T cells to adhesion molecule ELAM-1. Nature 349: 799-802, 1991.

32. Thomas W: Catch bonds in adhesion. Annu Rev Biomed Eng 10 39-57, 2008.

33. Hidalgo A, Peired AJ, Wild MK, Vestweber D and Frenette PS: Complete identification of E-selectin ligands on neutrophils reveals distinct functions of PSGL-1, ESL-1, and CD44. Immunity 26: 477-489, 2007

34. Matsuura N, Narita T, Hiraiwa N, Hiraiwa M, Murai H, Iwase T, Funahashi H, Imai T, Takagi H and Kannagi R: Gene expression of fucosyl- and sialyl-transferases which synthesize sialyl Lewis ${ }^{\mathrm{x}}$, the carbohydrate ligands for E-selectin, in human breast cancer. Int J Oncol 12: 1157-1164, 1998.

35. Lester SC1, Bose S, Chen YY, Connolly JL, de Baca ME, Fitzgibbons PL, Hayes DF, Kleer C, O'Malley FP, Page DL, et al: Protocol for the examination of specimens from patients with invasive carcinoma of the breast. Arch Pathol Lab Med 133: $1515-1538,2009$.

36. Martinez FO and Gordon S: The M1 and M2 paradigm of macrophage activation: Time for reassessment. F1000Prime Rep 6: 13, 2014.

37. Zhang QW, Liu L, Gong CY, Shi HS, Zeng YH, Wang XZ, Zhao YW and Wei YQ: Prognostic significance of tumor-associated macrophages in solid tumor: A meta-analysis of the literature. PLoS One 7: e50946, 2012.

38. Wei J, Cui L, Liu F, Fan Y, Lang R, Gu F, Guo X, Tang P and Fu L: E-selectin and Sialyl Lewis X expression is associated with lymph node metastasis of invasive micropapillary carcinoma of the breast. Int J Surg Pathol 18: 193-200, 2010.

39. Mei J, Xiao Z, Guo C, Pu Q, Ma L, Liu C, Lin F, Liao H, You Z and Liu L: Prognostic impact of tumor-associated macrophage infiltration in non-small cell lung cancer: A systemic review and meta-analysis. Oncotarget 7: 34217-34228, 2016.

40. Lawrence T and Natoli G: Transcriptional regulation of macrophage polarization: Enabling diversity with identity. Nat Rev Immunol 11: 750-761, 2011.

41. DeNardo DG, Barreto JB, Andreu P, Vasquez L, Tawfik D, Kolhatkar N and Coussens LM: CD4(+) T cells regulate pulmonary metastasis of mammary carcinomas by enhancing protumor properties of macrophages. Cancer Cell 16: 91-102, 2009.

42. Pigott R, Dillon LP, Hemingway IH and Gearing AJ: Soluble forms of E-selectin, ICAM-1 and VCAM-1 are present in the supernatants of cytokine activated cultured endothelial cells. Biochem Biophys Res Commun 187: 584-589, 1992.

43. Cowley HC, Heney D, Gearing AJ, Hemingway I and Webster NR: Increased circulating adhesion molecule concentrations in patients with the systemic inflammatory response syndrome: A prospective cohort study. Crit Care Med 22: 651-657, 1994.

44. Fassbender K, Mössner R, Motsch L, Kischka U, Grau A and Hennerici M: Circulating selectin- and immunoglobulin-type adhesion molecules in acute ischemic stroke. Stroke 26: 1361-1364, 1995

45. Gearing AJ, Hemingway I, Pigott R, Hughes J, Rees AJ and Cashman SJ: Soluble forms of vascular adhesion molecules, E-selectin, ICAM-1, and VCAM-1: Pathological significance. Ann N Y Acad Sci 667: 324-331, 1992.

46. Gearing AJ and Newman W: Circulating adhesion molecules in disease. Immunol Today 14: 506-512, 1993.

47. Koch AE, Turkiewicz W, Harlow LA and Pope RM: Soluble E-selectin in arthritis. Clin Immunol Immunopathol 69: 29-35, 1993. 
48. Leeuwenberg JF, Smeets EF, Neefjes JJ, Shaffer MA, Cinek T, Jeunhomme TM, Ahern TJ and Buurman WA: E-selectin and intercellular adhesion molecule-1 are released by activated human endothelial cells in vitro. Immunology 77: 543-549, 1992.

49. Hebbar M, Révillion F, Louchez MM, Vilain MO, Fournier C, Bonneterre J and Peyrat JP: The relationship between concentrations of circulating soluble E-selectin and clinical, pathological, and biological features in patients with breast cancer. Clin Cancer Res 4: 373-380, 1998.

50. Ferroni P, Roselli M, Spila A, D'Alessandro R, Portarena I, Mariotti S, Palmirotta R, Buonomo O, Petrella G and Guadagni F: Serum sE-selectin levels and carcinoembryonic antigen mRNA-expressing cells in peripheral blood as prognostic factors in colorectal cancer patients. Cancer 116: 2913-2921, 2010.

51. Gyorffy B, Lanczky A, Eklund AC, Denkert C, Budczies J, Li Q and Szallasi Z: An online survival analysis tool to rapidly assess the effect of 22,277 genes on breast cancer prognosis using microarray data of 1,809 patients. Breast Cancer Res Treat 123: $725-731,2010$
52. Cakar M, Balta S, Sarlak H, Akhan M, Demirkol S, Karaman M, Ay SA, Kurt Ö, Çayci T, İnal S and Demirbaş Ş: Arterial stiffness and endothelial inflammation in prediabetes and newly diagnosed diabetes patients. Arch Endocrinol Metab 59: 407-413, 2015.

53. Klimiuk PA, Fiedorczyk M, Sierakowski S and Chwiecko J: Soluble cell adhesion molecules (sICAM-1, sVCAM-1, and sE-selectin) in patients with early rheumatoid arthritis. Scand J Rheumatol 36: 345-350, 2007.

54. Kvasnicka T, Kvasnicka J, Ceská R, Grauova B and Vrablík M: Increasing plasma levels of soluble cell adhesion molecules (sE-Selectin, sP-Selectin and sICAM-1) in overweight adults with combined hyperlipidemia. Sb Lek 102: 473-477, 2001.

55. Sacanella E, Estruch R, Badía E, Fernández-Sola J, Nicolás JM and Urbano-Márquez A: Chronic alcohol consumption increases serum levels of circulating endothelial cell/leucocyte adhesion molecules E-selectin and ICAM-1. Alcohol Alcohol 34: 678-684, 1999. 